\title{
A Husserlian Theory of Indexicality ${ }^{1}$
}

\author{
Kevin Mulligan and Barry Smith
}

from: Grazer Philosophische Studien, 28 (1986), 133-63.

\section{$\S$ 1. Preamble.}

It is well known that Husserl's Logical Investigations contain the beginnings of an account of the meanings of indexical expressions, expressions whose meanings depend essentially on some sort of explicit or implicit pointing or indication [Anzeigen], and therefore on some contribution by the surroundings of speaker and hearer. Husserl in fact speaks explicitly of 'occasional expressions', that is of expressions like 'this' and 'that' whose meanings depend on features of the occasion of use, ${ }^{2}$ but it is possible to gauge the full implications of his explicit remarks on the problem of indexical or occasional meanings only if these are read in conjunction with what he says elsewhere in the Investigations, especially on the subject of perceptual judgments and proper names. Moreover, Husserl's deliberations on indication, perception and naming, as also what he has to say on demonstrative pronouns, spatial and temporal adverbs and tenses, must themselves be understood - like everything else in this work - as applications of a very general theory of meaning and of structure or dependence.

In what follows we shall set out Husserl's account of indexicality and develop it in various ways. Unlike Husserl himself - who retrospectively described his own account as an 'act of violence' ${ }^{3}$ - we are strongly of the opinion that this effort is worthwhile. ${ }^{4}$

\footnotetext{
${ }^{1}$ Thanks are due to the Alexander von Humboldt Stiftung for the award to Smith of a grant for study in Louvain and Erlangen where his portions of this paper where written. We should like to thank also Herman Philipse and Karl Schuhmann for comments on an earlier version. Neither of them will be satisfied with the results.

${ }^{2}$ Thus in LU I $§ 26$, he talks of 'okkasionelle' as opposed to 'objektive Ausdrücke'. Heinrich 1910, a dissertation based on Husserl's logic lectures of 1908, talks of 'deictic' expressions, and also of deictic functions and concepts.

${ }^{3}$ See the Foreword to the 2nd ed. of LU, p. 48. (Page references to the Logical Investigations, here and in what follows, are to the Findlay translation. This must however be used with care. Thus in place of 'act of violence' [Gewaltstreich], Findlay has here 'tour de force'.)

${ }^{4}$ It is by no means clear to us what particular features of his earlier account Husserl wanted to reject. Certainly none of his commentators has shown in any reasoned fashion what, if anything, Husserl
} 


\section{$\S 2$. Husserl's Aristotelian Theory of Meaning}

Husserl's general theory of meaning in the Logical Investigations is formulated within the framework of an Aristotelian theory of species and instantiation. All individuals instantiate species at various levels of generality, and, following a long tradition, Husserl thinks of species as arranged in trees whose top-most node is some highest material genus - for example living thing or mental act or physical event. Meanings [Bedeutungen] are identified with certain special sorts of species: meanings are those species which are - or could be $\mathrm{b}^{5}$ - instantiated by those parts or moments of really occurring acts which are their contents or matters (LU V § $16 \mathrm{f} ., \S 20) .{ }^{6}$ Meanings are universals; the contents or matters of acts are their individual instances. ${ }^{7}$

Not all acts can have meaning in the strict terms of this Aristotelian theory. Husserl divides acts into two broad classes: 1. judgments, questions, hypotheses and the like, which do have meanings; and 2. perceptions, perceptual memories, and so on, which do not (LU VI § 4f. and § 44). The latter cannot be expressed, since they have no meanings [Bedeutungen] to be expressed. That perception and meaning belong to

changed his mind about. Philipse's careful and in many respects definitive account (1982) has shown what role the phenomenon of occasionality played in Husserl's rejection of the LU account of meaning and the adoption of a new account in Ideas I. But we shall argue that the LU theory of meaning is in general superior to Husserl's own later theory, that his changes of mind - his abandonment of descriptive psychology as an end in itself and his adoption of a Cartesian and 'transcendentalist' metaphysics - are changes for the worse. Moreover Philipse does less than justice to the LU because he concentrates his attention on those passages where Husserl deals explicitly with 'occasional expressions'. Like so many other interpreters of Husserl's early philosophy, he fails to take into account Husserl's theories of perceptual judgments and of structure or dependence. Woodruff Smith's paper of 1982 also deserves a mention here, though his account of the LU theory seems to us to be constrained too narrowly within the framework of Husserl's later 'noema' theory, and to pay too little attention, in its account of demonstratives like 'this', to the distinction between cases where some relevant object exists and cases where such an object is lacking.

${ }^{5}$ In LU I $\S 35$ Husserl asserts that many Bedeutungen are not yet instantiated.

${ }^{6} \mathrm{We}$ shall use the terms 'content' and 'matter' interchangeably in what follows - though it is important to avoid confusion between content in the sense of matter, and 'representative content', a notion which will play an important role in our exposition later. A further distinction is that between content in the sense of matter and content in the sense of state of affairs: see Künne 1986, Mulligan 1986 and Smith 1986.

${ }^{7}$ Strictly speaking the meaning is instantiated by the content of the act taken together with its quality (as nominal act, judgment, question, etc.). See Smith 1987 for further details of this Aristotelian theory. Smith's paper includes also some consideration of those aspects of Husserl's theory which might more reasonably be classified as Platonistic. 
different spheres is clear already from the fact that the differences manifested by the former have the character of a continuum. As Husserl writes: 'Every chance alteration of the perceiver's relative position alters his perception, and different persons who perceive the same object never have exactly the same perceptions.' (LU VI § 4, p. 681) All positional and perspectival differences of this sort are irrelevant in the sphere of meaning. Broadly speaking we can say that the contents of perceptual acts cannot fall under those species which are characteristic for the contents of meaning acts because they have the wrong kind of articulation. ${ }^{8}$

Seeings and rememberings and imaginings, like judgings, namings, predicatings and assertings, are mental episodes. But although the former are not structured in the same way as the latter, they are not by any means lacking in all structure. ${ }^{9}$ Thus consider:

(1) Jules saw Jim

(2) Jules referred to Jim by using 'Jim' in the sentence...

(3) Jules saw that Jim was holding hands with Jane

(4) Jules judged that Jim was holding hands with Jane.

What is it, in the world, which would make the given sentences true? Husserl seems initially to have been tempted by the idea of seeing (1) and (2) as sharing in common the feature that their truth-makers are 'nominal acts', as contrasted with (3) and (4), whose truth-makers would be 'propositional'. Note that the opposition he has in mind here cannot be that of simple vs. complex. The main verbs of (1) and (2) may perfectly well take complex complements such as: Jim holding Jane's hand. Husserl's idea seems rather to have been that, just as, in the truth-maker of (2), Jules is directed to Jim by means of a single-rayed act of naming, so, in the truth-maker of (1), Jules is directed to Jim by means of a single-rayed act of perception. (LU V § 33) He was tempted also

\footnotetext{
${ }^{8}$ As Stephens puts it: 'If percepts were meaning-intentions - if they could be expressed in the strict sense - we could expect to find expressions whose meaningfulness we could account for only on the assumption that certain percepts are occurring. But what we find, on the contrary, is that the sense of our 'perceptual' claims and the percepts we undergo vary independently of one another.' (p. 121)

${ }^{9}$ In LU VI $\S 26$ and elsewhere Husserl does nevertheless suggest that there is a component of the perceptual act - its 'Auffassungssinn' - which is a meaning [Sinn] in a looser sense, and in fact somehow becomes identical with the Bedeutung of an expressive act in that process which is called fulfilment. For an attempt to make some sense of this idea see our discussions of fusion-phenomena in $\S 11$ below.
} 
by a similar account of the relation between (3) and (4), an account of a sort that has since become familiar from discussions of 'epistemic' or 'propositional' seeing (seeing that), for example in the work of Dretske.

The terminology of nominal and propositional acts is misleading, however, since it masks the fact that (1) differs from (2) in that its truth-maker contains a real part, Jules' seeing, whose content is, as we have just seen, not expressible. That is, the truth-maker itself contains a part that is neither propositional nor nominal because it is not an expressible content at all. ${ }^{10}$

\section{$\S$ 3. The Problem of Indexical Meanings}

But what precisely is to be said about the truth-maker of 'Jules saw that Jim was holding hands with Jane'? What is the status of those complex events which are perceptual judgings, i.e judgings founded on perceptions? Suppose, for example, that I assert, in suitable circumstances, 'There's a bird in that tree'. We must ask, first of all, what is the act in which the meaning of this assertion resides. It is not as though,

besides the sounds of the words, nothing further was given here, functioning in such a way as to determine the significance of this expression, other than the perception to which it attaches itself. For on the basis of this very same perception our utterance could have sounded quite differently, and thereby have unfolded a quite different sense. I could, e.g., have remarked: 'That is black', 'That is a black bird', 'That black creature is flying off', etc. (LU VI § 4, p. 681)

Husserl does not merely want to draw a general distinction between meaning and perception, he wants to insist further that, even in the case of perceptual statements, perceptions do not contribute any part of the meaning of the total act. This is seen most clearly in the fact that 'perceptions may not only vary, but also vanish altogether, without causing an expression to lose all its meaning' (loc. cit.). Even a statement such as 'I see that there's a bird in the tree', while it cannot be true unless the relevant perception occurs, can be meaningful whether this perception is occurring or not. ${ }^{11}$

There must, therefore, wherever a perceptual statement is made, be some other act which supplies the meaning. In our example this extra act is an act of judgment. But it

\footnotetext{
${ }^{10}$ Compare Husserl's own reservations about the "quite unsuitable term "nominal presentation"' in the Forward to the 2nd ed. of LU (p. 49), reservations which are perhaps connected also with his adoption of the view - after finishing the 1st edition of the LU - that the nominal components of expressed or expressible acts such as assertions or judgments are not independent parts of these.

${ }^{11}$ Cf. Stephens, p. 121.
} 
is not as if this judgment and the perception simply existed side by side with each other - as it were by accident. Judgment and perception are here connected together in a quite special way, which it will be our job in what follows to determine more precisely.

\section{§ 4. Species and Lowest Specific Difference}

For an act to have meaning, to be what we have called a meaning act, is for its content to have a certain specific sort of articulation, so that this content may instantiate a species of the relevant sort. In drawing a line between perception and meaning Husserl does not however want to defend a conception of perceptions as completely mute or inarticulate. Perceptions are meaningless, but this does not mean that their contents are lacking in all structure. As Stephens has shown in his comparison of Husserl's views with those of Dretske, Husserl can be taken to have shown that perception does not require "the possession or acquisition of concepts or beliefs, in the sense in which adult human beings - but not neonates, squirrels, and mosquitoes - can be said to have concepts and beliefs (the sort of thing that can serve as premise in an inference). ${ }^{12}$ As Husserl himself notes (e.g. at LU I § 13), to perceive an object is not yet to apprehend it conceptually. In this respect it is interesting that, like much recent work on indexicality, Husserl's theory, too, finds features of the use of proper names to be an important starting point in the understanding of indexicality. Essentially occasional expressions, he points out, are

much like proper names - if the latter function with their authentic meaning. For a proper name also names an object 'directly'. It means it, not in the attributive way as the bearer of these or those properties, but without such 'conceptual' mediation, as that which it 'itself' is, just as perception might set it before our eyes. (LU VI § 5 , p. 684)

The job of conceptually grasping a perceived object is performed by a judgment or some other, similar act - founded on the perception. The matter or content of the judgment is then determined in the last instance by the perception with which it is bound up. But now, what is the meaning of such a judgment? Clearly it can no longer be simply the species of the corresponding act matter. That element in the matter of the judgment in virtue of which the judgment is about the individual object supplied for it by the perception, is not something which can be accounted for in terms of the species exemplified by this matter taken in isolation. Meaning in the sense of species is here 'complete only down to the lowest specific difference'. This lowest difference is itself

\footnotetext{
${ }^{12}$ Stephens, p. 125; cf. Dretske 1966, esp. ch.1.
} 
provided by another act, an act of perception, which, as Stephens puts it, 'establishes indexical contact in a way which allows meaning to take over' (p. 171).

Husserl's own formulation is as follows:

Intuition may indeed be allowed to contribute to the meaning of a perceptual statement, but only in the sense that the meaning could not acquire a determinate relation to the object it means without some intuitive aid... Intuition in fact gives [the common meaning element] determinateness of objective reference, and thereby its last difference. And this achievement does not require that a part of the meaning must itself lie in the intuition. (LU VI $\S 5$, p. 683)

Thus Husserl's view is that the matter or content of an act of judgment of the given kind is such that, taken in specie, it is insufficient to supply a full meaning for the act in question. The last difference for this meaning must be provided by the act of perception on which the judging is dependent. The Aristotelian theory of meaning can thereby be saved, but only at the cost of allowing two quite different sorts of ways in which acts may have meanings.

An interesting passage from Shwayder's essay "Uses of Language and Uses of Words" will perhaps help to clarify some of the more arcane overtones of Husserl's account here. For 'species' one can also read 'kind' or 'second substance'. Shwayder introduces a terminology according to which:

A use of language is a kind of language action, the analogue in the realm of conventional action to an Aristotelian 'second substance' or 'substantial form'. I believe that the counterpart to Aristotle's thesis that every substance falls within a second substance holds for language: every language act falls within some one or several uses of language. This thesis, though hardly surprising, is of some significance, for I doubt that a comparable principle holds for entities of every kind, e.g., I doubt that every morsel of sand or every movement of a leaf is classifiable under some kind. (p. 134)

Shwayder makes his point only in connection with the expression components of a meaning act. Husserl, in contrast, argues quite generally that not only uses of signs but also all the components of the content of an act may fall under species or kinds. ${ }^{13}$

The structure of occasional utterances in the traditional sense (of utterances

\footnotetext{
${ }^{13}$ What Shwayder has to say is more generally inadequate if one accepts that everything falls under some kind, even those entities which manifest continuous rather than discrete variations.
} 
containing personal and demonstrative pronouns, etc.) is identical to that of perceptual

judgments just described. An occasional expression 'cannot, as a matter of necessity, be understood unless one directs one's attention either to the person uttering it or to the circumstances of utterance.' Whether or not the word can be understood 'depends on this directed looking as a sine qua non.' (LU I § 26, p. 314) The actual meaning of an occasional expression, its meaning on a given occasion of use,

is oriented according to the occasion, the speaker and the situation. Only by looking to the actual circumstances of utterance can one definite meaning be constituted for the hearer out of this group of connected meanings. Since we always understand such expressions in normal circumstances, the relevant presentation of these circumstances and of their ordered relation to the expression must involve the presence of generally graspable, sufficiently reliable clues to guide the hearer to the meaning intended in the case in question. (LU I § 26, p. 315)

\section{§ 5. Husserl and Competing Accounts}

We are now familiar with the core of Husserl's account of indexicality. It has two basic features. First, it stresses that indexical uses of language involve at least two materially distinct sorts of act: meaning acts and, in the central cases we have considered so far, perceptual acts. Second, it tells us how these acts are connected. The connection involves a relation of unilateral existential dependence of one event on another within the context of a certain type of complex whole. This structure is employed by Husserl at a number of places in the Investigations. What is most striking about its use in the description of the phenomenon of indexicality is that Husserl attempts to put more meat on the bare notion of the relation of unilateral dependence by introducing new but related structural notions belonging specifically to the sphere of language use and meaning. Chief among these are the concepts of implied meaning and fulfilment (Deckung, fusion) ${ }^{14}$

The core of Husserl's theory is that two acts (events) are involved (occur simultaneously, or nearly so) in indexical meaning and that the relation between these has a certain structure. How can we build on this core? We need to take account of at least the following dimensions:

A. The relation between the two kinds of act, between meaningful utterance and perception, must be considered from the point of view of both speaker and hearer. That is to say, we have to deal not only with the production of assertions and gestures

\footnotetext{
${ }^{14}$ See LU III $\S \S 8 f .$, LU VI, passim.
} 
and perceptual judgments on the part of the speaker but also with the processes of understanding of deictic utterances by the hearer and with the perceptual experiences bound up therewith.

B. The contents of meaningful utterances and of perceptions enjoy a range of different types of complexity. Meaningful utterances may or may not be propositionally articulated, and if they are, then they may or may not contain nominalisations. Perceptions may or may not be simple, and they may or may not be epistemic or propositional. Types of perception and types of meaningful utterance combine to yield types of indexical semiosis.

C. The correlates (objects) of meaningful utterance and perception interrelate in a variety of quite specific ways in indexical phenomena. We have to show how, on the basis of Husserl's account of the entities that make up the perceptual-discursive whole, it is possible to grasp the variety of indexical phenomena (the range and extent of the deictic field). These entities include: states of affairs and their components; the components of visual (tactile, etc.) space; the temporal components of a situation.

D. The opposition between positing and non-positing acts involves the presence or absence of a factor which belongs, in Husserl's terms, to the quality of an act: acts like perception and assertion involve a moment of belief or conviction in the existence of the associated object: acts like assumption are such that this moment is lacking. Other differences in act quality are reflected, for example, in the opposition between an act of visual memory and an act of current visual perception. But besides act quality and act matter Husserl acknowledges a third variable dimension within every act: the dimension of representative content. In general, the matter and representative content of an act form a 'whole...of two moments', i.e. they are two mutually dependent entities relative to the entire act. (LU VI § 25) The representative content of an act of meaning is made up by its constituent signs, that of a perceptual act by visual (tactile, etc.) sensations. On Husserl's account of indexicality the material within this third dimension that is grasped by a participant in an indexical exchange is qualitatively complex: it contains both signs, and sensations relating to something other than signs.

E. The relation between meaningful utterance and perception can be transposed to relations between one meaningful utterance and another. We shall argue that Husserl's account of the way certain acts supply the lowest specific difference for other acts provides the key to understanding the mechanisms of fulfilment (or illustration) which alone can explain the diachronic coherence of meaning acts (whether in successive utterances or, for example, in reading texts).

All of these five factors must all be taken into account if light is to be thrown on the biggest single problem within intentionalist ideational theories of meaning (of which Husserl's in the Investigations is the most thoroughly worked out version): namely the problem of the recoverability of meanings (species). This problem was recognised by 
Husserl in his Formal and Transcendental Logic $(\S 80)$ where, admitting that he was not able to deal completely with occasional judgments, Husserl refers to the way the senses of occasional judgments are essentially determined in a way which goes beyond what is or could ever be expressed determinately in words.

The more familiar treatments of indexicality fall into two broad groups: 1 . those that take into account the semiotic and logical aspects of the phenomenon, and 2. those that stress its psychological and functional aspects. To the first group belong the distinctions and theories of Peirce, Reichenbach and Russell (Frege and Wittgenstein belong here too). To the second group belong Bühler's increasingly influential discussion of the Zeigfeld (deictic field) and also work by Fillmore. ${ }^{15}$ Recent work by Dretske, Evans, Peacocke and Perry has begun to bridge the gap between the two sorts of approach, but our suggestion is that such authors are here to some extent recapitulating insights gained already by Husserl.

We shall deal in what follows particularly with logico-semantic treatments, attempting to reveal their deficiencies from the standpoint of the Husserlian theory. We draw inspiration from Künne's recent careful defence of a Frege-Wittgenstein theory of indexicality, though we shall argue that Künne fails to do justice to the combination of meaningful utterance and perception that indexicality involves. This, we shall suggest, is indicative of a deeper deficiency of Fregean theories of meaning. We also criticise the attempts of Føllesdal, Woodruff Smith and McIntyre to fuse together insights of Frege and the later Husserl to yield an account of indexicality. Frege, notoriously, neglects entirely to take account of the acts involved in deixis; Føllesdal et al. attempt to rectify this deficiency by grafting acts onto the Fregean semantic theory, but in such a way as to make it impossible to give any account of how acts might then combine with the relevant contents and objects.

The Husserlian account of indexicality, we are suggesting, indicates how the two approaches - the semiotic-logical and the psychological-functional - can be seen to complement one another. It offers a unified account of the relation between the different acts involved in producing and understanding indexical utterances (the intentionalist aspects of the situation) and of the categorial grammar of the signs used in such situations. And, in view of the recent upsurge of interest in intentionalist semantics and pragmatics and attempts to integrate such approaches into formal grammar, we believe it can be shown to satisfy what many now regard as the desiderata of a theory of indexical meaning, of deictic thinking.

\section{§ 6. Künne and the Frege-Wittgenstein Account}

\footnotetext{
${ }^{15}$ On Bühler see Ehlich 1979, Mulligan 1986a.
} 
Frege, too, came to put forward an account of indexical meanings, an account which - with all its deficiencies - can be said to be typical of positions adopted within mainstream analytic philosophy. As for Husserl, so for Frege, the circumstances of utterance may dictate part of the meaning expressed when a sentence is used indexically. In asserting a sentence containing an expression like 'now', Frege writes,

the time of speaking is a part of the expression of the thought... in all such cases the mere word (sound), as this can be fixed in writing, is not the complete expression of the thought; rather, one requires for its proper grasping [Auffassung] also knowledge of certain circumstances accompanying the utterance, which are used as means of expression of the thought. Finger-pointings, movements of the hand, looks, come into question here. (Frege 1918, p. 24 of trans.)

An expression like 'this F' or 'the F', Frege also tells us, often functions as a proper name - but

the proper name is then to be understood not as the concept-word alone, but as the whole made up of the concept-word, the demonstrative pronoun and the accompanying circumstances. (Frege 1914, p. 230, our emphasis)

In his important treatment of Frege's views on this subject, Künne takes what Frege says here quite literally. And he brings out the force of what Frege is saying by introducing the term 'hybrid proper name' to designate wholes of the given kind. The peculiar sort of complexity possessed by the hybrid proper names occurring in indexical utterances is such that they - i.e. the hybrid proper names themselves - comprehend both linguistic expressions and (parts of) non-linguistic 'situations' or 'circumstances'.

This is a crucial insight and we shall see shortly that it is central also to a Husserlian account of indexicality. In Frege's - and in Künne's - hands however, not only is it merely a part (an oversimplified part) of the story, but further: any attempt to build on the insight quickly reveals the weaknesses of the Fregean theory of meaning within which it is embedded. ${ }^{16}$

\footnotetext{
${ }^{16}$ As Künne usefully points out, the Wittgenstein of the 1930s set out a view of deixis that is very close to that of Frege. Moore relates that Wittgenstein

made a distinction... between what he called the 'sign' and what he called the 'symbol', saying that whatever was necessary to give a 'sign' significance was a part of the 'symbol' so that where, for instance, the 'sign' is a sentence, the 'symbol' is something which contains both the sign and also everything which is necessary to give that sentence sense... He illustrated this by saying that if a man says 'I am tired' his mouth is part of the symbol. (Moore 1970,
} 
Künne attempts to develop Frege's point as follows. The sense of a hybrid proper name (a complex expression, remember, containing as its parts for example the sign 'I', a speaker, and a time $t$ ), completes the sense of the predicate in an utterance such as:

(1) I have blood-group A

(made by $\mathrm{S}$ at $t$ ) to make a thought. This thought can be represented as

<the sense of $+($ 'I', S, $t)$, the sense of 'has blood group A'>

where the expression '+("I", S, $t)$ ' is an abbreviation of 'the hybrid proper name that consists of an occurrence of "I" produced by $\mathrm{S}$ at $t, \mathrm{~S}$, and $t$.' (Künne 1983, p. 65)

Künne gives a useful functorial account of the categorial grammar of hybrid names. Deictic expressions such as 'I' - he calls them indicators - are name-forming functors. Such a functor takes the situation of an utterance as argument to make a (hybrid proper) name, a name that has the peculiarity that it names part of itself. There are other examples of names that denote parts of themselves. This holds for example of the token quote occurring in a sentence such as: '* $\beta *$ is an occurrence of a Greek letter.'

As Künne points out, his reconstruction of Frege's theory satisfies two genuinely Fregean principles:

- To every sense there corresponds at most one Bedeutung.

- The Bedeutung of a proper name (singular term) is an object (in this case a special sort of complex whole).

But there are two problems with the reconstructed theory.

First, the hybrid proper name can only have a sense for an interlocutor if the speaker - in our example - is seen, is the object of an act of perception (and if this act of

p. 262)

Similarly, in the Philosophische Bemerkungen, Wittgenstein writes: 'What is characteristic about sentences of the sort "this is..." is only that the reality outside the so-called sign-system somehow enters into the symbol.' (p. 120, our emphasis) Künne's recognition that Wittgenstein is here making Frege's point in his own terminology - indexical sentences are signs and these, together with the circumstances of their utterance are components or parts of symbols - has the merit of illuminating passages that have puzzled other commentators on Wittgenstein. Like Frege's account of indexicality, however, Wittgenstein's is at best a simplified version of the account set forth in the LU. 
perception itself occurs at $t$ ). The 'grasping ${ }^{17}$ must be perceptual. This is not a problem within the Husserlian framework, of course, for there both linguistic and non-linguistic acts have a place. ${ }^{18}$

Second, Fregean senses - unlike Husserlian matters or contents - are abstract (i.e. non-spatio-temporal) entities and the notion of a complex entity that would somehow contain both spatio-temporal and abstract entities as parts - a notion that recurs at several places in Frege's philosophy and is surely indispensable to Künne's account of indexical senses - is, we claim, not merely 'hybrid' but incoherent. (As we shall see, the same incoherency is shared also by the noema-philosophy of the later Husserl.)

Thus we should argue that Frege's thesis that situations of utterance (or parts of such situations) are parts of the 'means of expression' that are involved in our grasping of indexical utterances is both important and true. But we should insist also that it is only within the framework of a theory of meaning and complexity of structure like Husserl's that the thesis - or its grain of truth - can be accommodated.

\section{§ 7. Categorial Grammar: Dependence and Modification}

What is Husserl's account of the structure of that complex event which is the grasping of the meaning of an indexical utterance? As we have already seen, such an event consists of two parts, one of which is dependent on the other. The dependent (unsaturated) part is the understanding of the meaning of the words uttered (this is itself complex: we can distinguish the propositional attitude involved, the signs used, their being heard, the thought they express); the independent (saturated) part is the perception of whatever it is that fills out the thought of the dependent part by providing its 'lowest difference'.

We shall see more clearly the relevance to the Fregean account of Husserl's talk of dependent and independent parts of the deictic situation if we look briefly at the theory of categorical grammar put forward by Husserl in his 4th Logical Investigation. For this theory, too, is an application of the general theory of dependence of the 3rd Investigation - i.e. of the theory of structure on the basis of which our account of the

\footnotetext{
${ }^{17}$ Frege's term 'Auffassung' is also used by Husserl, e.g. in the already mentioned passages in LU VI $\S 26$.

${ }^{18}$ Again and again, analytic work on indexicality is marked by this same omission. That is, we repeatedly find indexical utterances described as utterances whose meaning can only be grasped by 'taking into account the situation of utterance', but that the meanings of such utterances depend on perceptions of the situation of utterance is a fact which simply goes unnoticed. Evans 1982, e.g. p. 72 and ch.6, provides a notable exception to this rule.
} 
perceptual judgment has been constructed. ${ }^{19}$

According to the Husserlian theory of categorial grammar, the logico-grammatical form of an assertion or judgment of the simplest sort, e.g. 'Socrates is white' is to be expounded, crudely, as follows. The assertion consists of two parts, a subject-part and a predicate-part, combined together in virtue of the fact that the latter is unilaterally dependent on the former. Since Husserl's theory of meaning is Aristotelian, any and every occurrence of the assertion really possesses this logico- grammatical form, i.e. necessarily contains two assertion-parts: a referring and a predicating, in such a way that the one is dependent on the other. A meaningful use of '- is white' can occur only if combined with a meaningful use of some sign in the category name. For assertions of the form ' $\mathrm{aRb}$ ' there must occur three assertion-parts: one of which (corresponding to ' $R$ ') stands in two relations of unilateral dependence to the others (i.e. to referrings to $a$ and $b$, respectively).

This view of logico-grammatical form is controversial. Here we want only to point out its attractions for anyone concerned to connect the theory of logico-grammatical form with considerations relating to general cognitive theory (to the psychology of language and thinking and to the theory of perception).

For as we now see, Husserl can appeal to one and the same sort of relation unilateral dependence - to explain both

a) the connection between the sense of a deictic nominal component of a deictic utterance and the perceptual act that provides it with its own indexical content, and

b) the connection between the verbal component of this utterance and its nominal component or components.

Yet another feature of Husserl's theory of syntactic and semantic structure enables us to dig even deeper into the make-up of an indexical utterance. It will be remembered that Künne points out that both uses of hybrid signs in deictic utterances and uses of token-quotes are characterised by the peculiar fact that they name a part of themselves. In his 4th Investigation Husserl carefully distinguishes, alongside the operations and formation rules making up a categorial grammar, a further type of syntactic operation which he calls modification. The operation of modification takes us from a 'normal' to an 'abnormal' - yet still law-governed - use of an expression. Some of the examples he gives are familiar to linguists as transformations. They include all the different types of nominalisation and of suppositio, including that case where a word token or type is referred to by means of quotation marks.

The meaning normally corresponding to a use of the word 'and' is a dependent

\footnotetext{
${ }^{19}$ The 4th Investigation also stands at the beginning of modern work on categorial grammar, having influenced both Leśniewski and Ajdukiewicz.
} 
meaning (its instances are contents which depend for their existence on a context of other, neighbouring contents). If however we say " "and" is a conjunction', then the subject of our sentence is not this dependent meaning, but rather a new independent meaning. And because of this, "“and"' is not a syncategorematic, but a categorematic expression, a special sort of name: 'the change of meaning is regularly indicated [angezeigt] in our written expression by quotation marks, or by other varieties of what may suitably be called heterogrammatical modes of expression.' (LU IV $\S 11$, p. $514)^{20}$ Thus a token of a word combines with (tokens of) those indicating modes of expression we call quotation-marks to produce a whole which names a part of itself, that part which is an independent (categorematic) part of the complex expression obtained by syntactic combination.

What interests us here is Husserl's characterisation of modified uses of expressions as 'abnormal'. One justification for calling a use of a sign in one syntactic position normal and its use in another abnormal is that the capacity to engage in abnormal uses presupposes (is one-sidedly dependent on) the capacity to engage in normal uses. Thus clearly, no one knows how to use " $\beta$ "' properly who does not know how to use ' $\beta$ '. And part of what is involved in this condition is that, as Husserl puts it, the unmodified and modified uses of a sign must have some content in common. This claim has been partially vindicated by those philosophers who have argued - against Carnap - that uses and mentions of a sign are not disjoint but have something in common. As Garver puts it $(1965$, p. 231):

\section{(1) "cat"}

is an 'interesting function' of

(2) cat,

and not a mere conventional name thereof - since one cannot recognise what (1) denotes unless one knows that (2) is a word, the word mentioned in (1). Mention is a nominal linguistic function, but it differs from ordinary nominal functions of expressions in that it presupposes a grasp of the parts of the expression used to effect it.

Let us assume that Husserl's account of modified and unmodified sign-uses is defensible. Can we extend it to take into account the case where a situation of utterance (or part thereof) functions as part of a hybrid sign? The use of a situation to

\footnotetext{
${ }^{20}$ On indicated meaning see Woodruff Smith 1982, p. 200. On Husserl's theory of modification see $\S 5$ of Mulligan 1986.
} 
function as part of a sign is not a case of syntactic modification. But it is a case of modification in a more general sense of this term, a generalisation which was familiar to Husserl and his immediate followers. ${ }^{21}$ Any spatio-temporal entity can be employed as a sign (LU VI $§ 14$ ), but then any such use of an object that does not belong to a linguistic system involves an attitude to that object which is a modification of the normal attitude: imagine the use of a sign composed of spatial objects (tables, chairs, books), or of colour-samples, gestures or movements.

From what has been said, we can now conclude that there are cases where uses of or attitudes towards non-linguistic items enable these to function as parts of the representative contents of specific sorts of acts, and that this holds both for perceptual judgments and for graspings of deictic utterances. Acts of this sort involve modifications of attitudes to and uses of such items in normal acts. This has the initially somewhat paradoxical-sounding consequence that there is a modification of Jim's normal attitude to himself whenever he says ' $I$ '. That such a modification does in fact occur however, is seen in the fact that Jim is in such circumstances using himself as a sign.

\section{§ 8. Representative Content}

The notion of the representative content of an act thereby comprehends not only used, understood linguistic signs and sensations, but also (modified, abnormal) uses of other kinds of objects. Husserl in fact describes a category of acts whose representative content contains both linguistic (signitive) and non-linguistic components. He calls them mixed acts (LU VI § 25) - and here the echoes of Husserl in Künne's theory of 'hybrid' proper names should be obvious.

Our slight development of Husserl here is the claim that the complex act that is the grasping of an indexical utterance contains a mixed representative content some components of which are nominal signs while others are modified in the sense of our discussion above. In the grasping of an indexical utterance the representative content of the entire act consists both of the heard words and of visual sensations that mediate the perceived situation, object or a perceived profile thereof - and this representative content functions simultaneously 'both as a signitive' and 'as an intuitive representation' (LU VI § 25).

\footnotetext{
${ }^{21}$ See LU V, chs. 3-5. Reinach, especially, and also Meinong and his pupils, extended the notion of modification beyond the purely syntactic domain to comprehend also acts: thus Meinongian assumptions are modified acts of judgment. They are obtained by cancelling one of the features of judgment, namely belief. Similarly, a lie is a modification of a speech act of informing, alters this speech act in a determinate fashion: see Smith 1986a.
} 
Now according to the more usual interpretations of Husserl, representative contents are primarily a matter of sensations or, to use the later terminology, 'hyletic data', conceived as being in some sense immanent to consciousness. Particularly in the first edition of the LU however, Husserl is concerned to stress the close link between sensation and sensed object, which may even stand in a part-whole relation to one another (LU VI $\S 26$, cf. p. 740). Husserl is nearly always careful to include a reference to the represented thing or property whenever he refers to the representative content, even though he does not provide any general account of the precise relation between the two. Husserl's representational content is as a matter of fact always set out by him as the representation of a thing or property. ${ }^{22}$ The claim that perceptual judgments are varieties of mixed acts can then be seen to amount to the claim that they are in some sense in contact with their objects - that perceptual judgments, like perceptions in general, transcend the sphere of what can be described 'by purely phenomenological means'.

It is important to keep apart three further, related concepts distinguished by Husserl, though not with specific reference to indexicality. For any meaningful assertive utterance or thought we can distinguish:

1. the semantic relation of truth-making in which it may stand (to certain obtaining states of affairs)

2. an evidential or verificational relation in which it may stand (normally, again, to states of affairs - LU VI § 39)

3. its relation to whatever there may be 'outside' the thought or utterance which contributes to its content (and thereby potentially also to its meaning).

The distinction between 1 . and 2. is familiar (as also is its obliteration by contemporary proponents of 'anti-realism'). If 2. obtains then so does 1., though the converse implication does not hold. Whatever is verified must be true - for Husserl - but an assertion may be true even though unverified. 3. is exemplified most clearly by indexical utterances, where the latter's expressed meaning is supplemented by a perceptual act external to it, and the distinction between 2. and 3. may also be obliterated, for example in certain sorts of verificationism ('the sense of a sentence $i s$ the manner of its verification').

The peculiarity of indexical sentences, now, is that for all such sentences the right-hand relata of 1., 2. and 3. overlap. Part of what gives such a sentence its meaning

\footnotetext{
${ }^{22}$ We might even say that sensations are themselves the representative contents which result when things are 'used', rather than mentioned, in specific sorts of (perceptual) ways.
} 
is identical with part of what verifies it and with part of what makes it true.

Husserl's account of fulfilment in the 6th Investigation is designed almost wholly to accommodate cases in which what does the verifying (or falsifying) is not part of what provides a sentence with its meaning (2. and 3. are disjoint). The only exception is provided by indexical phenomena.

Consider, again, the case where Jules hears Jim saying 'that crow is flying high'. Jules only understands what Jim says, in the full sense, if he sees the relevant crow. Normally seeing the crow is part of seeing that the crow is flying high, which is what verifies Jim's claim. And any such verification implies that the claim is made true by what is seen.

One great attraction of Husserl's account of indexicality so far is that the relations of dependence to which appeal is made, like the relations 1. to 3., all relate real (that is to say, temporal) entities to one another, whether these be events of utterance and acts of meaning and perceiving, or states of affairs and parts thereof such as crows, flyings and finger-pointings. All of these entities will, as a matter of fact, instantiate species of various sorts. But the two levels of species and instantiation, of universal and particular, are kept rigidly apart. No attempt is made to understand the structures involved as hybrids out of real acts and spurious Platonic abstracta.

\section{§ 9. Noemata and Indexicality}

Husserl's later philosophy of meaning rests on an appeal to hybrid structures of just this sort, and involves an ontology of abstract meaning-entities in addition to the ontology of instances and species taken over from the Investigations. The most detailed interpretation of this later theory is that given by Woodruff Smith and McIntyre in their book Husserl and Intentionality, the greater part of which is devoted to providing a basis for a theory of indexicality within the framework of Ideas I. Following Føllesdal, Woodruff Smith and McIntyre canvas a Fregean interpretation of this work, conceiving Husserl's noemata as abstract meaning-entities, that is, as entities belonging to the same category as Fregean Sinne. The meaning of an act, according to this interpretation, is the abstract noema with which the act is bound up, and since all acts have noemata, it follows (trivially), that all acts have meanings in the terms of the theory in question. ${ }^{23}$ Husserl's earlier theory of meaning is ontological in nature; it describes the ways in which acts and their contents connect up with each other and with objects in the world in real structures of various sorts. This second theory, in contrast, at least as it is presented by Woodruff Smith and McIntyre, is a semantic

\footnotetext{
${ }^{23}$ We here ignore the complications of Husserl's distinctions between, e.g., noematic Sinn and noematic nucleus, which do not affect our argument.
} 
theory (which does not mean, however, that it is without an ontological price). It puts forward a picture of acts, meanings and objects as belonging to three heterogeneous realms, in such a way that connections between the first and third realms are effected 'semantically', via the intermediary abstracta in the second, which are supposed to prescribe which object (if any) an act is directed towards. And Husserl's reason for coming to embrace such a theory? For Woodruff Smith and McIntyre this turns on the fact that, if we were to deny the position that meaning is determined always by abstract noemata and is never contaminated by external realia, then:

Intentionality would no longer be, as Husserl held, a purely phenomenological property of consciousness, and it would no longer be something we can study by purely phenomenological means, by bracketing questions of the external world. ( $O p$. cit., p. 217)

The second theory therefore, at least in the form in which it is presented by Woodruff Smith and McIntyre, amounts to a type of Cartesianism. The twain of acts and transcendent objects are never allowed to meet. Woodruff Smith and McIntyre indeed attempt to impose a variant ('adverbial') form of Cartesianism on the LU itself:

Husserl's theory of intentionality in the Investigations, so far as it goes, is the sort of theory that would today be called an 'adverbial' theory: to see this black crow is to intend '(seeing this black crow)-ly', and so to have an experience of a certain type, a 'seeing-this-black-crow'-type of experience. (Op. cit., p. 142)

(The authors seem not to have realised that in using the word 'this' here they have already gone beyond the bounds of any coherent adverbial theory. ${ }^{24}$ )

That the second theory has a high ontological price follows from the fact that Husserl here continues to embrace (1) acts and their real contents and (2) the species thereof, alongside (3) the newly-introduced abstract 'noemata', giving no account of the relation which these new entities would bear to those already accepted. And nor, if we are right, can such an account be given, since it would involve once more the joining together of real and abstract entities within a single functional unity. As we suggested already in our discussion of Künne's reading of the Fregean theory above,

\footnotetext{
${ }^{24}$ There are, certainly, Cartesian elements in the Logical Investigations: Husserl was still at that time under the influence of Brentano. But Woodruff Smith and McIntyre do not strive to underpin their Cartesian reading of the LU by appeals to this source; rather they read back into Husserl's early theory elements taken over, lock, stock and transcendentally constituted barrel, from their version of his later phenomenology.
} 
there is no way in which a belief in wholes of this sort can be made coherent: treating noemata and concrete events as parts of a single unit is to run together entities on the level of meaning with what exists in material reality, a confusion of which Husserl's Aristotelian theory is never guilty.

How, now, do the two respective theories of meaning deal with the problematic case of the indexical act? On the LU theory the object of such an act determines or completes the meaning, provides its 'lowest difference', in the way we have described. Objects determine (parts of) the relevant meanings. On the noema theory, however, this order is reversed: the act itself - via its noema - prescribes the object. ('Prescription' thereby gradually melts away into 'constitution': the object itself, the object in reality, ceases to play any serious role within the theory.) Woodruff Smith and McIntyre recognise that this is an unsatisfactory view of the relation between an indexical act and its object. They see that when indexical acts occur it is necessary that something on the side of the object should play a role in determining the meaning of the act. But they recognise also that, to abandon the view that the noema 'prescribes the object', would be to admit into the theory a dimension which could no longer be 'studied by purely phenomenological means'. They seek to break out of this dilemma by allowing not the object but rather the context of the indexical act to function in determining the noema of the act. That is, they develop a conception of the meaning of such an act as an embodied or contextualised noema. It is not the abstract noematic content in itself that 'prescribes the object', in indexical cases, but rather

the content only insofar as it is embodied in that particular perceptual experience on that occasion - if you will, the demonstrative content-in-the-perception prescribes, or is satisfied by, the object of the perception, the object contextually before the perceiver. (Op. cit., p. 225, our emphasis)

The relation between a perceptual experience and its object would in such circumstances "be determined by the "external" context of the experience, rather than, as Husserl's basic theory of intentionality requires, by the "internal" content of the experience.' (Op. cit., p. 217) But once a position such as this is accepted for indexical acts, it is difficult to see why the theory of noemata as abstract entities is needed at all. For even in the case of non-indexical acts a real, embodied noema can always be found. And there is no reason why this latter should not be seen as doing the work which Woodruff Smith and McIntyre conceive to be performed by abstract noemata in the general case. But such embodied noemata are now virtually indistinguishable from the meaning contents of the Logical Investigations; they are in every case straightforwardly real and individual moments of the acts with which they are associated - a conception 
of noemata which Husserl himself came gradually to find attractive. ${ }^{25}$ One difference remains: the meanings of the LU are noetic, they are species of acts. Noemata, on the other hand, whether abstract or embodied, are supposed to belong somehow to the object correlate of the act. It is significant, however, that this difference can be specified only by appeal to the terminology of the later theory: the opposition of noesis and noema is simply not at home in the framework of the earlier work.

We conclude, therefore, that there is nothing which the noema theory can explain what the earlier theory cannot also explain - but with much less ontological ado.

\section{$\S 10$. The Pervasiveness of Indexicality}

The occasional meanings Husserl initially discusses in the Investigations are meanings attaching to the relatively restricted class of uses of expressions like 'I' and 'here' and 'now', and as already suggested Husserl does not in this work connect up his account of such expressions with his account of perceptual judgments.

By 1908, however, he had come to the conclusion that the entire class of sentences concerned with matters of fact were essentially indexical. ${ }^{26}$ In the already mentioned 1913 Foreword to the "Prolegomena" this change of mind is apparent in Husserl's reference to 'occasional meanings, to which, in strictness, all empirical predications belong' (p. 48). The recognition of the pervasiveness of occasionality is important not least because everything Husserl has to say about the relation between meaning acts and perceptual acts can now be seen as illustrating a much more general theory of the relation between relatively empty and relatively filled components of acts of all varieties.

But what did Husserl have in mind in affirming that all empirical predications are occasional? To answer this question we shall need some new terminology. Let us call those meaning acts that are not fully determined acts with an empty slot. A meaning act with an empty slot cannot, as a matter of necessity, occur unless there occurs an act which fills the slot (LU VI § 5, p. 683). Some other meaning act may occur in its place - where 'perceptions vanish altogether' the 'expression may continue to be meaningful, it need not lose all its meaning, ${ }^{27}$ - but the meaning will then not be the meaning of an act whose lowest difference stands in need of determination by some other act.

We have been concerned so far with those meaning acts with an empty slot whose

${ }^{25}$ Cf. Küng 1976, Hoche 1982.

${ }^{26}$ Cf. Bernet 1979, p. 51, Philipse 1982, p. 176; Husserl's thinking at this stage is in many respects similar to that of the Munich phenomenologist Johannes Daubert: see Schuhmann and Smith 1985.

${ }^{27} \mathrm{Cf}$. the passage from LU VI $\S 4$, quoted above. 
occurrence necessarily involves the occurrence of some act of perception. We have seen that no perceptual act, and in particular no perceptual act which serves as fundament for an act with an empty slot, is such that its content instantiates any of the species which are characteristic for meaning acts. It would be wrong, however, to conclude that the contents of perceptual acts cannot be described. As already noted, a perceptual act, for Husserl, is not something that is simply inarticulate. The contents of perceptual acts admit of very detailed specifications, but these are of a different type from the specifications of the contents of meaning acts: they include specifications such as up-down, right-left, here-there, figure-ground, etc., specifications which involve a reference to the structures of visual, tactile or olfactory fields (dealt with by Husserl in the lectures on Ding und Raum). Thus both the meaning act with an empty slot and its perceptual filling can be specified, independently of one another.

\section{§ 11. Generalisations of the Theory: I. Slots and Fillers}

There are, however, examples of acts with an empty slot where the filler act is not straightforwardly perceptual: the combination of a meaning act with an empty slot, on the one hand, and a perceptual filling act, on the other, is one special case of a more general phenomenon of 'illustration'. Thus a meaning act with an empty slot can be filled also - this much should be obvious - by acts of imagination, memory, expectation, etc. This is indeed recognised by Husserl himself (LU VI $\S$ 4f., p. 686). But there is nothing to stop us here from going even further. We may include meaning acts themselves among those acts that may serve as filler acts for meaning acts with an empty slot. Husserl takes this step in the 3rd chapter of the 6th Investigation, where he describes relations of partial fulfilment between meaning acts.

This extra step provides us with a first relatively uncontoversial generalisation of the cases considered by Husserl. Consider, say, a Boston sinologist who spends the greater part of his life wading through the Chinese press. Let us suppose that, after perusing some particular bundle of newspapers, he sits down to write a memorandum. Part I of the memorandum simply retails - with liberal quotations - the contents of the different items he has read. Part II then develops these contents, putting forward more general reflections on, say, the current state of Chinese naval policy. As in the simple perceptual case, so here, the founded acts of judgment which make up Part II express what is given in the filler acts in Part I; these acts of judgment might have been quite different, might have unfolded quite different aspects of the items presented, but they would nevertheless remain directed to the content of these items - and hence, mediately, to China herself.

Consider, now, the case of someone who reads only the second part of the memorandum, someone for whom the filler acts 'vanish altogether'. Such a reader would certainly grasp meaningful claims, but the judgments he would take in would not 
be determinate, as would those of a reader who had absorbed Part I (or, a fortiori, of a reader who had his own direct relational contact with the Chinese Navy).

A further step we want to take in order to display the full potential generality of a Husserlian account of indexicality involves denying that indexicality is a feature which is to be found only in acts enjoying a certain sort of articulate complexity. Husserl's perceptual judgments, like other, more complicated cases, are characterised by the presence of at least two distinct acts that combine in a law-governed way to form a single complex act. The majority of our cognitive acts, however, do not exhibit this clear separation of distinct components; rather, to use Husserl's term, the filled and the filling features are most commonly fused together. Nevertheless, as Husserl saw, it is in principle possible to analyse out what is fused together in an act (just as it is possible to determine which primary colours have been blended together to form a given mixture). Given any assertion, for example, it is enough to ask what its precise meaning is and what evidence the speaker has for making it. The attention of the speaker will thereby, at least in normal circumstances, be directed along channels which will enable a separation of the appropriate sort to be effected. In asking such questions we are typically rewarded by further assertions, having features qualitatively identical with features of the original assertion. The one sequence of assertions enables us to separate out the meaning of the original act, the other enables us to separate out, inter alia, any indexical component it may involve. Of course, only some of the evidence thereby separated out will simultaneously have an individuating function for correlated meanings. But wherever this is the case, the act thereby specified will have been, at least in this one respect, indexical.

Such sequences of assertions, culled from speakers in the way described, form temporally extended wholes which are structured by relations of dependence. Every specification either of the evidence or of the meaning content of a mental act is not only temporally posterior to this act, it is also dependent upon it.

But now our expanded Husserlian account of indexicality is able to cope with a range of cases in which complicated practices contribute explicitly and implicitly to the sense of what we say. For it is not merely isolated meaning components and isolated indexical components which can become fused together in the way indicated: all complex processes of training and every sort of working one's way into a discipline or subject-matter will involve the fusion of complex manifolds of such components, not at random but in determinate orders. And then just as the specification of the meaning of certain very simple indexical acts is provided by a specification of a type of filler act in terms of the principles of individuation for visual, tactile, etc., objects, so too the specification of the meanings of higher order indexical acts - belonging to a certain theoretical discipline or to a complicated practice of some other sort - is provided by specifying a type of filler act in terms of the principles of individuation relevant to the 
theoretical domain or practice in question. And here it is important to note that we have not assumed, in our general description of the fusion of meaning and evidence in cognitive acts, that the specifications by means of which the meaning is separated out can be produced only by the owner of the given mental content. We leave open the possibility that others - e.g. teachers, and authorities in general - can produce superior specifications of what an individual really meant. Indeed the very ability to discern the difference between the contribution made by evidence to an assertion, on the one hand, and its meaning on the other hand, is something that has to be learnt.

We can summarise the results of our discussions so far as follows: where relevant filler acts - in some cases a whole determinately ordered network of relevant filler acts - are not present, or do not serve, mediately, as foundation, then what we say is not determinate and must fail, at least in part, to link up with objects in the world. We can now, however, go one step further. The relation between meaningful assertion and perception is a complex of positing acts: both assertion and perception involve belief. The same is true of assertions and filler-assertions of the sort considered above: all involve or presuppose the attempt to establish a linkage to reality of the given sort. By dropping this restriction, however, and by including within the theory also non-positing acts, it becomes possible to do justice to parallel phenomena involving filler acts, for example in our reading of fiction, and thus to provide an account of what Bühler calls Deixis am Phantasma. (1934, § 8)

\section{$\S 12$. Generalisations of the Theory: II. The Meanings of Proper Names}

We should like to claim that our generalisation of the Husserlian theory of indexical meaning beyond the simple perceptual case is faithful to the spirit of Husserl's early philosophy. This claim receives some independent support from Husserl's account of simple and complex meanings set out in $\S 3$ of the second edition of the 4th Investigation. We have already seen that Husserl treated the meanings of indexical expressions as importantly similar to the meanings of proper names. Here he sketches a theory of the meanings of proper names which does justice to the variety of ways in which uses of proper names secure reference to objects in the world.

Husserl rejects two familiar accounts of proper names. He rejects first of all the view that proper names simply have no meanings. Thus whenever we "meaningfully use a proper name', he writes, this use instantiates a meaning species. Each use of the same proper name 'means the same thing and in the very same sense' (LU IV § 3, p. 496f.) And he rejects also, as we have already seen, the idea that the meanings of proper names are attributive in the sense that is required by the view of proper names as 
disguised descriptions. ${ }^{28}$ Proper names and definite descriptions are distinct varieties of linguistic phenomenon and a thinking through or use of the one is not the same as a thinking through or use of the other. As Geach puts the matter, the theory that proper names are disguised definite descriptions is, from a psychological point of view, 'palpably false; when I refer to a person by a proper name, I need not either think of him explicitly in a form expressible by a definite description, or even be prepared to supply such a description.' (1957, pp. 66f. $)^{29}$

Proper names, for Husserl, have simple meanings. But Husserl also claims that simplicity of meaning does not exclude a certain sort of complexity of content. There are, he writes in the 1st edition of the Investigations, 'meanings that bear in themselves certain distinguishable moments, but not in the form of articulated particular meanings; they are not complexes of meanings but they are still complexes of contents.' (LU IV $\S 4,1$ st ed., A 292)

Husserl now goes on to affirm that the simplicity of the meanings associated with uses of proper names precisely requires such complexity of content: 'the consciousness of meaning which attaches to proper names', he writes,

has a certain double-sidedness: there are two directions in which one can here talk of complexity or simplicity. One side fixes the simplicity or complexity of the meaning itself, and here we have the pure essence of the meaning as such; to it alone belongs the intentional essence of our concretely full meaning-consciousness which, regarded in specie, is the meaning.

In the case of the meanings of proper names this meaning is simple,

but it necessarily presupposes a wider intentional background of content, for the very reason that the same thing, referred to in the same sense (or univocally named by the same proper name) can be very differently presented, with a variable set of determining marks, and that it must be presented with some such set - but the variation and complexity of this set do not touch the meaning itself. (LU IV § 3, p. 497; our emphasis)

As we saw already above, not all contents exemplify species which are meanings. We shall refer to those contents which do not exemplify such species as presentational

\footnotetext{
${ }^{28}$ See the quotation from LU VI $\S 5$ in $\S 4$ above.

${ }^{29}$ Like Husserl, Geach argues that proper names have a partial meaning. On this view see Kripke 1980, p. 115, n.58.
} 
contents [Vorstellungsinhalte], noting that, as is suggested by our discussions in the previous section, not all presentational contents need be intuitive (i.e. contents of the sort we find in perceptual acts): when we speak of presentational contents we mean not only images, but whatever comes into the mind of the speaker when he refers to or thinks about or is in some way directed towards a given object, whether concrete or abstract.

We can now formulate what Husserl is saying here as follows: every use of a proper name which involves a meaning act also involves, as a matter of necessity, some presentational content, which may be either intuitive or non-intuitive. ${ }^{30}$ Such presentational contents are characterised by the feature of variability, in the sense that on different occasions of use of the same proper name qualitatively different presentational contents may be involved: 'the presentational content with which Schultze is presented when we name him can change in many ways whilst his proper name goes on performing in one and the same identical way, always naming the same Schultze "directly".' (LU IV § 3, p. 496)

Presentational contents vary in a way which depends both on the context of a given act and also on an individual's history. Just as, in the case of perceptual statements, acts of perception provide the meanings of expressions attached to them with their final determination, so the complexes of presentational contents associated with uses of proper names provide the necessary final determination of the proper name meanings from case to case. It is in virtue of the latter that objects are given as 'determinate and typically determinable - whether as a physical thing, an animal, a human being, etc.' (LU IV § 3, p. 497). Without them 'an actual meaning could not point to the object it means, and so not really be a meaning at all.' (LU IV § 3, p. 496)

Proper names are of course normally used not alone, but in sentences of varying degrees of complexity. The meaning contents bound up with proper names therefore normally stand in lateral relations of syntactic and semantic dependence with the meaning contents associated with uses of expressions from other semantic categories. Now, however, we can see that such meaning contents are in addition one-sidedly dependent on complexes of presentational contents of various sorts. Here too, therefore, the dependence relation that is at the basis of categorial grammar is seen to be at work also in connecting up our acts of meaning with the wider context of a surrounding reality.

Kevin Mulligan (Graz/Konstanz)

\footnotetext{
${ }^{30}$ Anton Marty, another pupil of Brentano, also held a theory of proper names very much along these lines: see Gabriel 1987.
} 
Barry Smith (Manchester)

\section{References}

Bernet, R. 1979 "Bedeutung und intentionales Bewußtsein. Husserls Begriff des Bedeutungsphänomens", Phänomenologische Forschung, 8, 31-64.

Bühler, K. 1934 Sprachtheorie. Die Darstellungsfunktion der Sprache, Jena: Fischer, 2nd ed., 1965.

Dretske, F. 1969 Seeing and Knowing, London: Routledge and Kegan Paul.

Dreyfus, H. L., ed. 1982 Husserl, Intentionality and Cognitive Science, Cambridge, Mass.: MIT Press.

Ehlich, P. 1979 Linguistisch-philologische Untersuchungen zum hebräischen deiktischen System. Verwendungen der Deixis beim sprachlichen Handeln, 2 vols., Frankfurt: Lang.

Eschbach, A. ed. 1986 Karl Bühler's Theory of Language, Amsterdam: Benjamins.

Evans, G. 1982 The Varieties of Reference, J. McDowell, ed., Oxford: Clarendon.

Fillmore, C. 1972 “Ansätze zu einer Theorie der Deixis”, in F. Kiefer, ed., Semantik und generative Grammatik, 1, 147-75, Frankfurt: Athenäum.

Frege, G. 1914 "Logik in der Mathematik", first published in H. Hermes, et al., eds., Nachgelassene Schriften, Hamburg: Meiner, 1969, 219-70.

- 1918 “Der Gedanke”, Eng. trans. "The Thought”, by A. and M. Quinton, in P. F. Strawson, ed., Philosophical Logic, Oxford: Oxford University Press, 1968, 17-38.

Gabriel, G. 1987 "Why Proper Names have Meaning: Marty and Landgrebe vs. Kripke", in Mulligan, ed., 1987.

Garver, N. 1965 "Varieties of Use and Mention", Philosophy and Phenomenological Research, 25, 230-38. 
Geach, P. T. 1957 Mental Acts, their Content and their Objects, London: Routledge and Kegan Paul.

Heinrich, E. 1910 Untersuchungen zur Lehre vom Begriff, Göttingen: Kaestner.

Hoche, H.-U. 1982 "Beziehungen zwischen der Semantik Freges und der Noematik Husserls", Archiv für die Geschichte der Philosophie, 64, 166-97.

Husserl, E 1900/01 Logische Untersuchungen, 1st ed., Halle: Niemeyer; 2nd ed. 1913/22, both now collected as Husserliana vols. XVIII and XIX/1, XIX/2. English translation of 2nd ed. by J. N. Findlay, Logical Investigations, London: Routledge and Kegan Paul, 1970. (LU)

- 1907 Ding und Raum. Vorlesungen 1907, as collected in Husserliana XVI, The Hague: Nijhoff, 1973.

- 1913 Ideen zu einer reinen Phänomenologie und phänomenologischen Philosophie, Erstes Buch, Halle: Niemeyer, collected as Husserliana, vol. III/1, III/2.

- 1929 Formale und transzendentale Logik, Halle: Niemeyer, collected as Husserliana XVII. English translation by D. Cairns, Formal and Transcendental Logic, The Hague: Nijhoff, 1969.

Kripke, S. 1980 Naming and Necessity, Oxford: Blackwell.

Küng, G. 1976 "Das Noema als reelles Moment" in P. J. Bossert, ed., Phenomenological Perspectives, The Hague: Nijhoff, 151-53.

Künne, W. 1983 "Indexikalität, Sinn und propositionaler Gestalt", Grazer Philosophische Studien, 18, 41-74.

- 1986 "The Intentionality of Thinking: The Difference between Propositional Matter and State of Affairs", in Mulligan, ed., 1986.

Moore, G. E. 1970 "Wittgenstein's Lectures in 1930-33", Philosophical Papers, London: Allen and Unwin, 252-324.

Mulligan, K. 1986 "Promising and Other Social Acts: Their Constituents and Structure", in Mulligan, ed., 1986. 
- 1986a “On Structure: Bühler's Linguistic and Psychological Examples”, in Eschbach, ed.

Mulligan, K., ed. 1986 Speech Act and Sachverhalt: The Philosophy of Adolf Reinach, Dordrecht/Boston/Lancaster: Nijhoff.

- 1987 Mind, Meaning and Metaphysics. The Philosophy and Theory of Language of Anton Marty, Dordrecht/Boston/Lancaster: Nijhoff.

Philipse, H. 1982 "The Problem of Occasional Expressions in Edmund Husserl's Logical Investigations", Journal of the British Society for Phenomenology, 13, 168-85.

Schuhmann, K. and Smith, B. 1985 “Against Idealism: Johannes Daubert vs. Husserl's Ideas I”, Review of Metaphysics, 38, 763-93.

Shwayder, D. S. 1960 "Uses of Language and Uses of Words", Theoria, 26 as revised in G. Parkinson, ed. Theory of Meaning, Oxford: Oxford University Press, 128-40.

Smith, Barry 1986 "On the Cognition of States of Affairs” in Mulligan, ed., 1986.

- 1986a "Materials Towards a History of Speech Act Theory", in Eschbach, ed.

- 1987 "Logic and Formal Ontology", in J. N. Mohanty and W. McKenna, eds., Husserl: A Textbook, Athens, Ohio: Ohio University Press.

Stephens, J. W. 1978 Phenomenology and Realism. An Essay on Husserl's “Logical Investigations”, Dissertation, Princeton.

Woodruff Smith, D. 1982 "Husserl on Demonstratives: Reference and Perception”, in Dreyfus, ed., 193-213.

Woodruff Smith, D. and McIntyre, R.1982 Husserl on Intentionality, Dordrecht: Reidel. 